\title{
Association between a ruptured distal anterior inferior cerebral artery aneurysm and arteriovenous malformation fed by the same artery
}

\author{
Guilherme Brasileiro de Aguiar', José Carlos Esteves Veiga ${ }^{1,2}$, \\ Felipe Jorge Oberg Feres ${ }^{1}$, Maurício Jory ${ }^{1}$, Mário Luiz Marques Conti ${ }^{1}$
}

Distal aneurysms of the anterior inferior cerebellar artery (AICA) are rare ${ }^{1-4}$ and only few cases located in its medial branch have been reported ${ }^{2}$. Their occurrence in combination with high-flow lesions in the same arterial territory is even more striking ${ }^{1,5}$. We report on a case of a patient with spontaneous subarachnoid hemorrhage (SAH), whose diagnostic investigation indicated the presence of arteriovenous malformation (AVM) and aneurysm in the AICA and perform a review of the literature.

\section{CASE}

A 58 years-old man had a sudden onset of headache. The computed tomography (CT) scan showed Fisher IV $\mathrm{SAH}$ in basal cisterns and fourth ventricle with incipient hydrocephalus (Figure A-B). The cerebral angiography showed a left distal AICA aneurysm associated with AVM, which was fed by the AICA (Figure C-D). Due the suspicion of the aneurysm rupture, the patient underwent initially to endovascular treatment of the aneurysm and later, to a ventricular peritoneal shunt. After one week, a left retrosigmoid craniotomy was performed for resection of the AVM in the cerebellopontine angle, which had become attached to the facial nerve (Figure E). The evolution (Figure F) was uneventful and he was discharged in good conditions.

The angiographic control showed resolution of both lesions (Figure F).

\section{DISCUSSION}

The association between a peripheral AICA aneurysm and AVM in the same artery is unique ${ }^{5}$. Distal AICA aneurysms are very rare ${ }^{2,5}$ with an incidence of $0.0003-0.5 \%$, and tend to occur in its meatal segment or dorsolateral branch ${ }^{5}$. Aneurysms associated with an AVM fed by the same arterial trunk reportedly account for only 2.8 to $9.3 \%$ of all cerebral $\mathrm{AVMs}^{5}$. According to Lee et al..$^{5}$, the association of a distal AICA aneurysm with an AVM fed by the same artery has been described in only 11 cases until 2009.

The clinical presentation of distal AICA aneurysms usually includes sudden-onset SAH or the gradual onset of cerebellopontine angle signs ${ }^{5}$. Pedicle aneurysms in feeding vessels are frequently associated with hemorrhage $^{3}$. According to Ishii el al. ${ }^{3}$, feeding vessel pedicle aneurysms appear to occur more frequently in conjunc-
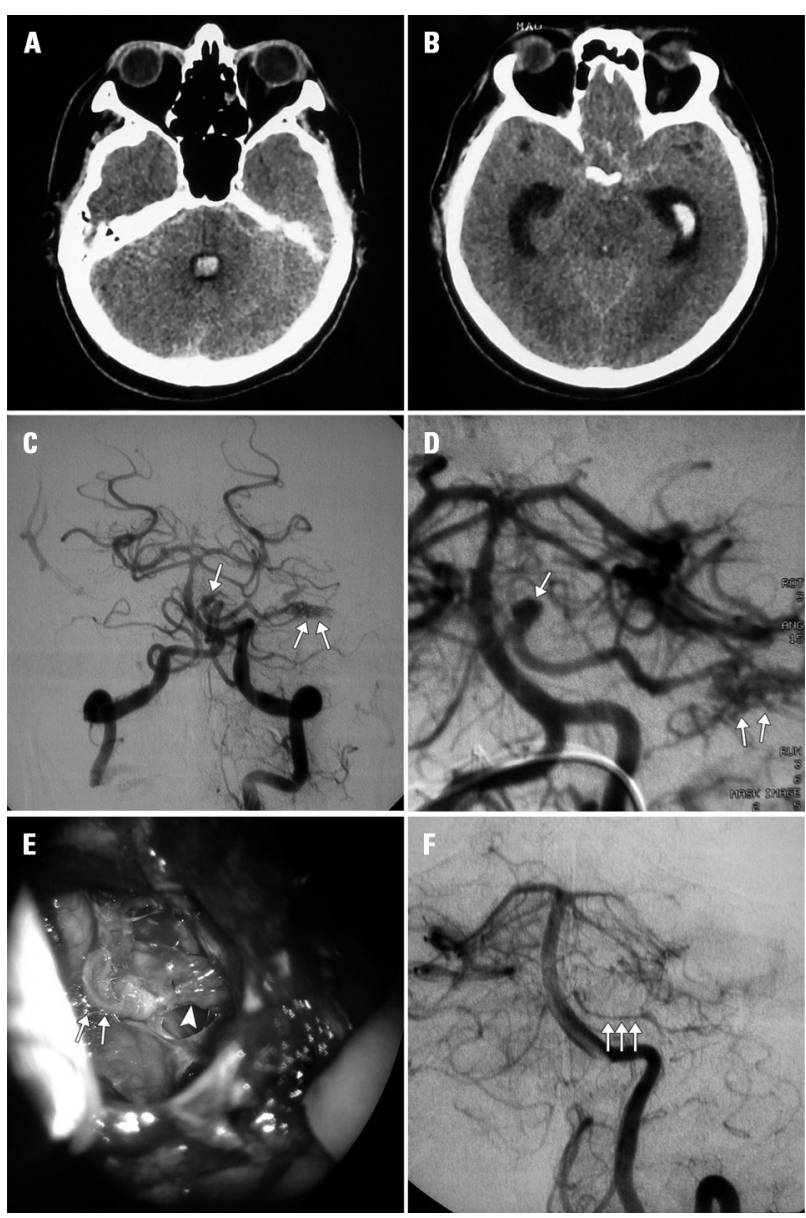

Figure. $[\mathrm{A}$ and $\mathrm{B}] \mathrm{Cranial} \mathrm{CT}$ scan showing SAH in cisterns of the base, with intraventricular hemorrhage and incipient hydrocephalus. [C and D] Left vertebral artery angiography in frontal $[\mathrm{C}]$ and left anterior oblique [D] views showing distal AICA aneurysm (arrow) and AVM (double arrow) in topography of cerebellopontine angle fed by the AICA. [E] Intraoperative image showing the AVM (double arrow) on the left facial nerve (arrowhead). [F] Left vertebral artery angiography in frontal view, after treatment, showing exclusion of the aneurysm and the AVM from circulation, with AICA preservation (triple arrow). 
tion with infratentorial AVMs, which justifies aggressive management to prevent high morbidity associated with ruptured aneurysms.

The pathogenesis of distal cerebellar aneurysms remains unclear ${ }^{5}$. In the distal cerebellar arteries, the morphology and possible higher hemodynamic stresses could contribute to dissection and subsequent formation of aneurysms ${ }^{3}$. Thus, the presence of a lesion like an AVM, that increases blood flow through a blood vessel, causes a certain hemodynamic burden to the vessel wall and in turn stimulates the formation of an aneurysm in it ${ }^{1,5}$. Surgical treatment should be directed towards the pathology responsible for the hemorrhage and then, the asymptomatic lesion ${ }^{5}$. According to Ishii et al. ${ }^{3}$, the distal AICA aneurysm is often wide-necked or fusiform, and may be difficult to clip.

In conclusion, the association between ruptured distal AICA aneurysm and AVM represents a very rare condition. Treatment should be directed to the two lesions, using various surgical approaches, depending on their location and neurovascular intimacy with the brain stem.

\section{REFERENCES}

1. Menovsky T, André Grotenhuis J, Bartels RH. Aneurysm of the anterior inferior cerebellar artery (AICA) associated with high-flow lesion: report of two cases and review of literature. J Clin Neurosci 2002;9:207-211.

2. Mizushima H, Kobayashi N, Yoshiharu S, et al. Aneurysm of the distal anterior inferior cerebellar artery at the medial branch: a case report and review of the literature. Surg Neurol 1999;52:137-142.

3. Ishii D, Takechi A, Shinagawa K, Sogabe T. Endovascular treatment for ruptured distal anterior inferior cerebellar artery aneurysm: case report. Neurol Med Chir (Tokyo) 2010;50:396-399.

4. Figueiredo EG, Paiva WS, Teixeira MJ. A distal AICA aneurysm. Arq Neuropsiquiatr 2009;67:112-114.

5. Lee SH, Koh JS, Bang JS, Kim GK. A Case of ruptured peripheral aneurysm of the anterior inferior cerebellar artery associated with an arteriovenous malformation: a less invasive image-guided transcortical approach: case report. J Korean Neurosurg Soc 2009;46:577-580.

ASSOCIAÇÃO ENTRE ANEURISMA RÔTO DA ARTÉRIA CEREBELAR ANTERO INFERIOR DISTAL E MALFORMAÇÃO ARTERIOVENOSA NUTRIDA PELO MESMO VASO

'Department of Surgery, Division of Neurosurgery, Santa Casa Medical School, São Paulo SP, Brazil; ${ }^{2}$ Chief of the Division of Neurosurgery, Santa Casa Medical School, São Paulo SP, Brazil.

Correspondence: Guilherme Brasileiro de Aguiar - Rua Cesário Motta Jr 112 01221-900 São Paulo SP - Brasil. E-mail: guilhermebraguiar@yahoo.com.br Received 6 May 2011. Accepted 14 June 2011. 